\title{
At spise \\ - ikke kun et spørgsmål om mad
}

Tidsskrift for Forskning i Sygdom og Samfund

Nr. 14, 2011 


\title{
Tidsskrift for Forskning i Sygdom og Samfund
}

\author{
Nr. 14: At spise - ikke kun et spørgsmål om mad
}

\section{(C) 2011 forfatterne og udgiverne.}

Redaktion:

Mette Bech Risør (ansv.), Forskningsenheden for Almen Praksis, Universitetet i Tromsø

Torsten Risør, Allmennmedisin, Institutt for Samfunnsmedisin, Universitetet i Tromsø Gitte Wind, VIA University College, Aarhus

Peter Vedsted, Forskningsenheden for Almen Praksis, Aarhus Universitet

Ann Dorrit Guassora, Forskningsenheden for Almen Praksis, Københavns Universitet

Susanne Reventlow, Forskningsenheden for Almen Praksis, Københavns Universitet

Rikke Sand Andersen, Forskningsenheden for Almen Praksis, Aarhus Universitet

Gxsteredaktør:

Birgit H. Petersson, Medicinsk Kvinde- og Kønsforskning, Københavns Universitet

Peer review foretages af et tværvidenskabeligt panel bestående af bl.a. læger, antropologer, filosoffer, historikere, psykologer, politologer og sociologer.

Proof: Thomas Christian Mikkelsen.

Layout og prepress: Ea Rasmussen.

Tryk: Werks Offset, Højbjerg.

Udgiver:

Foreningen Medicinsk Antropologisk Forum,

Afd. for Antropologi og Etnografi, Aarhus Universitet, Moesgård, 8270 Højbjerg.

Bestilling, abonnement, henvendelser og hjemmeside:

Tidsskrift for Forskning i Sygdom og Samfund.

Afd. for Antropologi og Etnografi, Aarhus Universitet, Moesgård, 8270 Højbjerg

Torsdag k1. 9-12, tlf. 89424597, email: sygdomogsamfund@hum.au.dk

Hjemmeside: www.sygdomogsamfund.dk

Artikler online: ojs.statsbiblioteket.dk/index.php/sygdomogsamfund/index

ISSN (tryk): 1604-3405

ISSN (online): 1904-7975

Tidsskriftet er udgivet med støtte fra Forskningsrådet for Kultur og Kommunikation.

Formål:

Tidsskrift for Forskning i Sygdom og Samfund er et tværfagligt tidsskrift, der tager udgangspunkt i medicinsk antropologi. Tidsskriftet har til formål at fremme og udvikle den forskning, der ligger i grænsefeltet mellem sundhedsvidenskab og humaniora/samfundsvidenskab. Tidsskriftets målsætning er at fungere som et forum, hvor disse fag kan mødes og inspirere hinanden - epistemologisk, metodisk og teoretisk - i forskellige forskningssammenhænge. Tidsskriftet formidler den debat og teoretiske udvikling, der foregår i de voksende faglige samarbejds- og forskningsinitiativer, der udspringer af dette grænsefelt. Tidsskriftet henvender sig til alle med interesse for forskning i sygdom og samfund og i særlig grad til sundhedsmedarbejdere i forsknings- og undervisningssammenhæng med forbindelse til tværfaglige miljøer.

Aims and scopes

The Journal for Research in Sickness and Society is an interdisciplinary journal which has a theoretical background in medical anthropology. The aim and purpose of the journal is to promote and develop research in the borderland between the health sciences and the humanities/the social sciences. The goal of the journal is to function as a forum in which these disciplines may meet and inspire each otherepistemologically, methodologically and theoretically. The journal conveys the debate and theoretical development which takes place in the growing collaboration and research initiatives emerging from this borderland. The journal addresses all with an interest in research in sickness and society and especially health professionals working with education and/or research in interdisciplinary institutions. 


\section{Indhold}

Torsten Risør, Ann Dorrit Guassora \& Birgit H. Petersson

Introduktion 5

Kjetil Wathne

Being stout: on health and lifestyle-change 17

Marie Højlund Bræmer

Det sure med det søde; diabetiske liv og moralske måltider i Vietnam 35

Dorthe Brogård Kristensen \& Charlotte Bredahl Jacobsen

Mad, kontrol og subjektivitet 57

Tenna Doktor Olsen \& Anna Marie Fisker

Madens rum - handler patienternes spiseoplevelse ikke også om arkitekturen omkring måltidet? 75

Alexandra Brandt Ryborg

Madmagi: at spise sig ud af en adfærdsforstyrrelse 87

Beth Elverdam

Velbekomme: familien i madkassen - om madpakker, kultur, historie og forbundethed 105

Abstracts in English 123

Forfatterliste 129

Skrivevejledning 133

Beskrivelse af nummer 15136 


\section{Velbekomme $^{1}$ : familien i madkassen - om madpakker, kultur, historie og forbundethed}

\section{Beth Elverdam}

Danmarks Pædagogiske Universitetsskole, Aarhus Universitet elverdam@dpu.dk

Elverdam, B. (2011). Velbekomme: familien i madkassen - om madpakker, kultur, historie og forbundethed. Tidsskrift for Forskning i Sygdom og Samfund, nr. 14, 105-121.

I artiklen inddrages forskellige materialer og teorier til at belyse det specielle ved "madpakken". Madpakken og dens format har været næsten uændret fra den blev etableret og til $n u$, hoilket siger noget om dens funktionalitet. Madpakken er en integreret del af familiens dagligliv og belyser madklassifikation og måltidskultur. Samtidig er madpakken symbol på den enkelte families kultur, idet madpakken tilpasses og tilberedes $i$ den enkelte familie. I madpakken udtrykkes smagspræferencer og identitet. Samtidig er madpakken speciel, fordi den spises et andet sted, end den tilberedes, i en anden kulturel kontekst; børnehaven eller skolen. Madpakken bliver således bærer af familiens forbundethed og symbol på familien. En familie, hois ansvarsområder er under forandring. Netop fordi madpakken smøres i én sammenhæng for at blive spist $i$ en anden og institutionel sammenhæng gør, at der er forskellige aktører: familien, institutionspersonale, medier og politikere, som alle har forskellige holdninger til, hvordan madpakken bør være, eller hvad den kunne erstattes med, og netop $i$ sammenstødet mellem disse holdninger fremstår madpakkens symbolværdi. 
Denne artikel handler om madpakker. Målet er at forstå hvad en madpakke er og den betydning, den er bærer af. Udgangspunktet er det konkrete indhold i en række danske børns madpakker og deres familiers tanker om dem. Madpakkens indhold analyseres ud fra den betydning det tillægges, og den symbolik, madpakken udtrykker. Samtidig inddrager jeg et historisk perspektiv, fordi en forståelse af historien og hermed madpakken som kultur-historisk fænomen kan give os en dybere forståelse af madpakkens symbolske betydning. Madpakken, som vi kender den i dag i Danmark, har ikke en lang historie, men dens tilsyneladende stabilitet tyder for mig på, at der er tale om et veludviklet og tilpasset koncept med stor funktionalitet.

\section{Mad, kultur og identitet}

Mit udgangspunkt for at forstå madpakken er antropologien og dens arbejde med mad som kultur. Antropologien er optaget af mad som kulturel orden i sin analyse af spisning som social praksis (Martin 2003: 162). Jeg har især ladet mig inspirere af antropologer, som arbejder med mad som klassifikation, identitet og mad som en del af den familiebaserede socialiseringsproces.

Indenfor den strukturalistiske antropologi er man optaget af madens struktur. For eksempel er Levi-Strauss (1997), optaget af de grundlæggende madklassifikationer (råt - tilberedt (kogt/stegt) - råddent) også kaldt den kulinariske trekant. Douglas, derimod, er optaget måltidets struktur, i forhold til, hvad der udgør et rigtigt måltid (a proper meal). Ifølge Douglas er mad og måltider lige så strukturerede som sproget, og mad skaber orden og kan ses som en symbolsk kondensering af vores tilværelse (Nielsen 2003). Samtidig var Douglas en af de første, som fik udført feltarbejde omkring måltider og madkultur, konkret blandt engelske arbejderfamilier. Observationer som både beskrev hverdagens praksis, men også ideologien især omkring middagsmaden (1974).

Samtidig spejler mad sociale praktikker, og:

"Food practices are implicated in a complex field of relationships, expectations, and choices that are contested, negotiated and often unequal" (Watson \& Caldwell 2005: 1).

Mad relaterer således til mere og andet end familien. Noget der bliver tydeligt når den politiske debat drejer sig om mad i institutionerne, når det organiseres 
som udbragt mad til børnene. Her er der ingen valgmuligheder, intet spillerum for egen smag. Her tydeliggøres sammenhængen mellem mad og politik, dels i forhold til det, der reelt kan spises, og statens ønske om at styre det, der bliver spist.

Mad og identitet hænger ubrydeligt sammen.

"Food is a strong cultural marker, and thus an integral part of a person's identity" (Delaney 2004: 274).

Ifølge Delaney er vi det vi spiser, individuelt og kulturelt. Mad er helt grundlæggende symbolet på identitet. Mennesker reproducerer hvem de er gennem den mad de spiser, og mad skaber kulturelt set forskelle. Ifølge Douglas organiseres mad i det spiselige og det ikke spiselige. Men samtidig organiseres maden i måltider, som har specifikke navne og indhold. Det hun betegner som "meal format" som kombinationen af tilrettelæggelse, servering og ingredienser (Nielsen, 2003:120). Madpakken er et meal format.

Samtidig er måltider noget man kan spise sammen med andre, men ikke alle andre, oftest familie og venner, eller børnehave- og klassekammerater. Måltider er også omgærdet med regler. Hvad spises der, hvor spises der og hvordan spiser man? Måltidet handler både om det rette mad og den rette måde at spise på.

Det er gennem socialiseringen i familien at den enkelte udsættes for og lærer de kulturelle madklassifikationer. Nielsen (2003) ser på maden med udgangspunkt i den franske sociolog Bourdieu. Ifølge Bourdieu er det vi gør ikke tilfældigt. Vi betjener os af præferencer, og disse præferencer er noget, vi har lært i barndomshjemmet, som igen kan trække sine præferencer til andre tidligere barndomshjem. Præferencerne skal ses i lyset af habitus, som er "de erfaringer, erindringer og vaner, der er indprentede i kroppen som bestemte dispositioner " (Nielsen 2003: 212). Det er en slags grammatik som sætter rammen for vores gøren og laden, og ligesom grammatikken virker klassificerende. "Disse klassifikationsskemaer er via familie og opvækst indskrevet i kroppen", og ikke mindst er de så at sige "gået os i blodet" og er derved - ikke bevidst og uden at vi tænker nærmere over det - bestemmende for, hvorledes vi handler tænker og vurderer (Bourdieu refereret i Nielsen 2003: 212). Douglas' holdning er at samtiden er overfokuseret på den enkelte som forbruger, det hun kalder "the desocialized individual dominating social thought" (Douglas 2003: 6) og har alt for lidt opmærksomhed mod betydningen af det sociale, specielt i relation til mad og spisning. I denne artikel er det således familien som er udgangspunktet. 


\section{Forbundethed}

I sin ph.d.afhandling om barnløshed bruger antropologen Tine Tjørnhøj-Thomsen begreberne forbundethed og fællesskab. Hvor fælleskab opstår i grupper der organiserer sig, f.eks barnløse, er forbundetheden etableringen af varige bånd. Begreberne henter hun fra antropologen Strathern, som bruger dem til at beskrive slægtskab. "Slægtskab - som det er blevet karakteriseret i Vesteuropa (se fx. Strathern 1993) - vedrører en konkret relationel kontekst, hvor slægtninge omgås hinanden i forhold til specifikke forventninger om slægtninges indbyrdes forbundethed. Men slægtskab refererer også samtidig til forestillinger om, hvorledes personer, identiteter, relationer og særlige former for forbundethed bliver til" (Tjørnhøj-Thomsen 1998: 3). Sagt på en anden måde refererer fællesskab til noget konkret - det at være sammen - og forbundethed som et mere symbolsk udtryk for følelsen af fællesskab. Også antropologen Carsten bruger begrebet forbundethed (connectedness) i sin analyse af slægtsskab. For hende er forbundethed noget der etableres i en social praksis (Carsten, 2004). Hendes udgangspunkt er at forbundethed netop udtrykkes i det, hun kalder "the interface" mellem hverdagsintimiteten (den nære) og den ydre verden (Carsten, 2004: 26). Hvor den nære verden er hjemmet og familien, med den tilhørende madlavningserfaring, smag og spisevaner.

Begrebet forbundethed vil jeg bruge i forbindelse med analysen af madpakken. Mit fokus er ikke slægten, men familien og dens medlemmers indbyrdes forbundethed. Familien er ikke en prædefineret enhed, men kan være forskellige konstruktioner hvori der indgår madsocialisering i en konkret hverdag. I den "sunde" ${ }^{2}$ familie som jeg henter empirisk materiale fra, blev familie defineret som mindst en voksen med et barn under 10 år. Familien og hjemmet er stadig den mest habitualiserende faktor (Nielsen 2003).

"Habitus er også det, der forårsager, at vi fantaserer om mad i fastlagte baner, men disse skal forstås bredt, som en slags smagens rammebevilling" (Nielsen 2003: 122).

Carsten gør opmærksom på, at det netop er spisningen at og tilberedningen af maden, der viser, hvem der hører sammen, og etablerer og understreger denne forbundethed (Carsten 2004: 37 og 41). Desuden understreger hun at hjemmet (og maden) har betydning som erindring senere i livet (2004:27). En erindring, som hun mener, har 'vivid emotional power'. Erindringen om hjemmets mad - og madpakken fra hjemmet - indeholder sådan en følelsesmæssig magt. En magt, som etableres gennem forbundethed. 
Jeg har tidligere vist hvordan danske familier gennem mad og spisning udtrykker deres ønske om og forventning til et hyggeligt familiesamvær omkring aftensmaden (Elverdam 2003). Men samtidig udtrykker de en forbundethed mellem forældre og børn gennem madpakken, dens tilblivelse, spisning og en eventuel tilbagetagning af det ikke-spiste. Både middagsmaden og madpakken siger noget om familien og familiens identitet. Maden er med til at adskille den ene familie fra den anden på samme måde, som der engang var store forskelle på, hvad man spiste i de enkelte samfund i landet. Tidligere havde denne variation baggrund i det, man producerede på stedet, således at der var stor forskel på hvad fiskefamilien, bondefamilien og borgerfamilien spiste. Nu er de fleste fødevarer tilgængelige for alle, og derfor bliver det man spiser (og køber), i langt højere grad et udtryk for valg, som indkøberen træffer på familiens vegne.

\section{Madpakken i historisk kontekst}

Mad eksisterer altid i en historisk og samfundsmæssig kontekst og derfor er det relevant at forstå, hvor madpakken kommer fra. De sidste 200 års udvikling har i Danmark, som i mange andre lande, ændret samfundet fra at bestå af mindre samfund med en udpræget selvforsyningsøkonomi. Det man spiste producerede man selv, hvad enten man levede som bønder eller som fiskere. Det er først i forbindelse med urbaniseringen og industrialiseringen, at fødevarer bliver noget man køber, det vil sige varer produceret af andre. Varer som købes og betales med penge, man selv har tjent ved at arbejde for andre. Denne udvikling betyder dels at man er nødt til at deltage i en pengeøkonomi, dels at flere varer bliver tilgængelige, f.eks. sukker.

I tiden 1870-1920 skete der en vældig omvæltning i danskernes spisevaner, idet madpakken, den kolde mad, rugbrød med pålæg, erstattede den varme middagsmad. I første omgang alene for dem der gik på arbejde, men siden, da alle efterhånden kom på arbejdsmarkedet og børnene i institution, blev der smurt madpakker til børn og begge forældre. Samtidig blev aftensmaden til den varme middagsmad vi kender i dag. Madpakkens fremkomst var en nødvendighed for arbejderne, der blev betinget af en nedskæring af middagspausen fra 2 til 1 time. Det betød at arbejderne ikke som hidtil kunne nå hjem og spise varm mad. Maden måtte tages med på arbejde og det blev i form af madpakker. Borgerskabet opgav også den varme mad, men de spiste smørrebrød, ikke madpakker. Der opstod hurtigt i byerne høkere, som solgte færdigsmurte madpakker, og viktualiehandlere, som specialiserede sig i alene at sælge pålæg til madpakker. 


\section{Madpakkerne i de "sunde" familier}

Oplysninger om indholdet i en række konkrete madpakker stammer fra et tværfagligt forskningsprojekt som tog udgangspunkt $\mathrm{i}$ danske børnefamiliers praksis $\mathrm{i}$ det levede hverdagsliv, og det sundhedsbegreb, de levede med i hverdagen. Dette er udførligt beskrevet i Elverdam \& Sørensen (2003) ${ }^{3}$. Det indskriver sig i den antropologiske interesse i mad og måltider, som den er udviklet efter 1990. Projektet var med sin tværfaglighed, metodisk og teoretisk, karakteristisk for samtidens madforskning.

Familierne, som deltog i undersøgelsen, havde alle meldt sig selv. Det var en strategi vi valgte fordi vi gerne ville have, at de deltog i flere forskellige undersøgelser: at veje maden, at blive interviewet under indkøb, at blive interviewet hjemme og lave mad til og spise sammen med forskerne. Nogle familier blev også interviewet af psykiatere og som afslutning blev alle familierne (ad 2 omgange) inviteret til spisning og diskussionen af madreklamer sammen med forskergruppen. Familierne var således familier med ressourcer og med denne type forskning kan det ikke blive anderledes. Men alligevel vil resultaterne fra en sådan unders $\varnothing-$ gelse altid samtidig beskrive omridsene af mere generelle og delte madprincipper, både som levet hverdag og som ideal (se i øvrigt Møhl (2003) for refleksioner over, hvilket perspektiv antropologen får fat i).

Der meldte sig 23 familier, og heraf deltog 21 i alle undersøgelser, undtagen reklameaftenen hvor 19 familier deltog. Familierne vejede al deres mad i en uge. De førte skemaer over hvert enkelt familiemedlem, hvad de spiste, og hvor meget det vejede. Ifølge ernæringsforskerne er der så lidt variation i vores madvarer, at en uges vejning er tilstrækkelig til at vurdere kosten generelt.

I indkøbsinterviewene blev der også købt ind til madpakker og det var muligt at observere, hvem der puttede hvad i indkøbsvognen, og samtalerne omkring det. I relation til madpakkerne går det igen i interviewene at hvis børnene er med til at købe ind, er de med til at bestemme hvilke varer der bliver indkøbt til madpakken. Madinterviewene foregik hjemme hos familierne og tog udgangspunkt i det, familierne konkret spiste i løbet af dagen. De beskrev den sidste dags måltider og indhold. Herved blev også de konkrete madpakker beskrevet, ligesom vi spurgte til variationer og forandringer. I disse interview var det muligt at spørge børnene om, hvad de konkret havde haft på maden. Det de beskrev var oftest en helt traditionel madpakke, f.eks '2 halve med leverpostej' (Boel (fam. B - 7 år). Denne udtalelse kunne sammenlignes med barnets vejeskema som viste hvad hun havde spist i madpakken over en uge og de andre familiemedlemmers mad- 
pakker. I dette tilfælde stod pigens udtalelse i kontrast til moderens fortælling om alt det spændende man kunne gøre med madpakker og som hun, som pædagog, syntes at forældre var forpligtede til. Hvis vi ser moderens forventninger som udtryk for en samfundsbåren ideologi om madpakker, og datterens udtalelse som udtryk for familiens daglige praksis, vil jeg tolke det som et udtryk for den traditionelle madpakkes levedygtighed. En praksis, som er i modsætning til en ideologi, som kommer udefra om at gøre madpakken mere tidssvarende/spændende, og som blandt andet bliver formidlet i dag- og ugeblade samt nu på hjemmesider, f.eks. hos Fødevareministeriet.

I vejeskemaerne er det relativt enkelt at udskille madpakkens indhold. Jeg har ikke taget drikke (mælk, juice, vand) med, fordi det jeg er optaget af, er de klassifikationer, man kan gøre indenfor madpakkens mere faste (i fysisk forstand) elementer, fordi det er dem, der kan sættes sammen på forskellig måde. Jeg har alene taget de 5 hverdage, idet familiernes frokost i weekenden ofte var meget anderledes, fordi den ofte kombineres med morgenmaden, en brunch eller de spiste noget som analytisk meget mere lignede aftensmaden (fælles mad, fælles spisning - dog ikke nødvendigvis samme indhold). I relation til registreringen af madpakken er det interessant at langt de fleste noterer hvert enkelt stykke mad i rækkefølgen: brød, smør, pålæg, pynt. Hvis registreringen følger tilberedningen (og det er sandsynligt) smøres madpakken som individuelle stykker og ikke i en form for "samlebåndsarbejde". I analysen af madpakker i denne artikel indgår madpakker fra 36 børn i alderen 3-13 år. Efterfølgende har jeg gennemgået alle de kvalitative interview, som alle varede flere timer, for oplysninger om madpakker.

Børn er ikke en homogen masse, men kan opdeles i flere forskellige kategorier i relation til den mad de spiser til frokost. En opdeling der både understøttes i mit materiale og hos Haastrup (2003) er: børnehavebørn, som får madpakke med og bringer ikke-spist mad tilbage). De yngre skolebørn op til 3.-4. klasse, som har madpakke med, spiser sammen med læreren og bringer ikke-spist mad tilbage. De store 5.-6. klasse børn, som har madpakke med, spiser alene i klassen og ikke tager ikke spist mad med hjem. De største elever, har højst sandsynligt ikke madpakke med. Flere af de ældste børn i de "sunde" familier spiste først når de kom hjem efter skole; det fremgik af vejeskemaerne. I forbindelse med den "sunde" familie, gennemførte vi en spørgeskemaundersøgelse blandt repræsentativt udvalgte børnefamilier i Danmark. I denne undersøgelse svarede $86 \%$ af børnene mellem 7 og 20 år at de havde en madpakke med og $61 \%$ at de havde en med hver dag (Olsen, 2003, 76). 


\section{Madens symbolik}

Forbundetheden er den symbolske værdi om sammenhæng som udtrykkes gennem maden eller relateret til maden. Det er når bordet dækkes til morgenmaden, og familiens medlemmer indtager maden samme sted, men ikke samtidig, ligesom de ikke spiser det samme. Her er bordet symbolet på familiens enhed, de er forbundet men der er ikke nogen samvær, idet de ikke fysisk er samlede omkring bordet, men tværtimod hver udlever deres individualitet og egne gøremål. Familien er ikke samlet som en enhed. Vi ser det samme omkring frokosten indtaget på arbejdet eller institutionen. Hvis den, som madpakke, bringes med hjemmefra, f.eks. af børnehave- eller skolebarnet, udtrykker den forbundethed. Forbundetheden kommer dels til udtryk symbolsk, maden er smurt hjemme, med kærlighed fra forældrene eller $\mathrm{i}$ et socialt samvær med børnene. Det er tydeligt, hvordan denne forbundethed udtrykkes, nemlig gennem det, der fungerer som en lille hilsen hjemmefra: lidt chokolade, et stykke kage.

\section{Når madpakken smøres}

Hjemmet og familien er stadigvæk rammen om en væsentlig del af danskernes madkultur. Vi taler stadig om at smøre, selvom smørret er væk og erstattet med andre produkter. I de deltagende familier blev madpakken smurt enten om morgenen eller om aftenen, enten af barnet selv (under supervision) eller en af forældrene. Madpakker er noget man snakker om, og hvor børnenes kommentarer bliver hørt. I familien $\mathrm{N}$ fortalte moderen om datterens madpakke: "Nønne, hun vil jo slet ikke have kød med, undtagen lige nogen små stykker pølse eller sådan, så det er sådan lidt. Hun vil gerne have brødet med smør på eller, så hun får en masse grøntsager med, og brød og ja, hvad ellers får du med?" Med det sidste spørgsmål, hvor moderen beder datteren om at svare, lægger hun op til, at det er den, der spiser madpakken, der bestemmer indholdet. Datteren svarede: "rugbrød med smør, nogen gange en bolle med eller en grovbolle med, og så nogen gange et stykke slik". I familien O var der 5 drenge, hvoraf de 4 var mellem 6 og 13 år. Hver smurte sin egen madpakke. Far sagde "og de ved også, hvordan de vil have det, det gør de, og det er de gængse ting, det vi kalder 'luxuslet', er leverpostejmadder og rosin og makrel, en dåsemakrel, Orm [på 11/2 år], han kan slikke dåsen med makrel til det sidste".

Omkring madpakkerne udtrykker familierne forskellige holdninger. Dels at madpakkens indhold er individuelt, dels at man har et fællesskab omkring smøringen af madpakken. Det er gennem smøringsprocessen, at relationen skabes 
mellem spiseren og indholdet og mellem forarbejdningen og familien. En mor siger "hvis de fär spegepølse, som de kan lide eller leverpostejmad eller makrelmad, det der bliver spist, så synes jeg at det er fint, så kan de få råkosten hjemme" (fam. D).

\section{Madpakkens indhold}

Hverdagslivet er præget af gentagelser det er nødvendige, for at kultur skal kunne fremstå som kultur og ikke en samling tilfældige hændelser. Kultur må nødvendigvis indeholde og bære præg af gentagelse, spor og mønstre. Derfor er der ikke noget at sige til, at madpakken alene ændrer sig langsomt på samfundsplan.

Som sagt smøres madpakkerne nedefra og op. Det vil sige altid i rækkefølgen rugbrød, smør, pålæg. Familierne gjorde meget ud af at specificere, at brødet kan være: rugbrød, hjemmebagt brød, ciabattaboller, groft rugbrød, fuldkornsrugbrød mm. Denne opdeling understreger, at brød ikke kun er brød, men kan klassificeres efter indhold og funktion. At groft brød kædes sammen med hverdag og arbejde, er også beskrevet af Jakobsen \& Jensen (2007). Det næste er smøringen, hvor der ikke er smør, det spiste man i weekenden, men enten plantemargarine eller et blandingsprodukt - eller hos nogle enkelte, ingenting.

Pålægget var: leverpostej, spegepølse, rullepølse, kyllingepølse, skinke, kogt kød, fisk (tun, makrel, torskerogn). Enkelte fik salater, ost, kogt kartoffel og æg. Andre fik middagsrester i form af f.eks. tærte. Ud over dette var der: pålægschokolade og figenpålæg. Derudover var der rå frugt og grøntsager: agurk, tomat, gulerod, kiwi, spansk peber, banan, appelsiner, klementiner, samt slik: chokolade, kiks med nøddecreme, kage, digestive.

Inden for den enkelte familie var der et repertoire af muligheder og derudfra træffes der individuelle valg - sådan som det også fremgår i citaterne. Det samme gælder det enkelte barns madpakkes sammensætning i vejeugen: der var variation, men indenfor nogle bestemte rammer. Nogle børn havde større variation end andre, men der var, bortset fra formatet, ingen fremherskende mønstre. Der er meget lidt alders- og årstidsvariation i madpakkerne.

Set historisk er der sket ændringer, idet de rå grøntsager og slikken er en ændring i madpakkens sammensætning. Hvis vi tænker lidt med Lévi-Strauss (1997), har madpakken ændret sig fra at være ren kultur (alle ingredienser enten kogte eller forarbejdede på anden måde som smørret), til at være en hybrid af natur (de rå grøntsager og frugt) og kultur og indeholder nu elementet slik der, som vi skal vende tilbage til, falder udenfor klassifikation. 
Madpakkens betingelse er at den ikke skal spises der, hvor den smøres, men transporteres et andet sted hen, f.eks. daginstitution eller skole, for at blive spist sammen med nogle mennesker, som ikke er familie, og som måske har andre ideer om, hvad en madpakke skal indeholde. Madkassen skal være let at åbne for små børnehænder, og maden skal være let at pakke ud. Det skal være let at skabe overblik over det totale indhold i kassen - som en del af beslutningsprocessen om hvad der skal spises eller ikke spises. De enkle madder skal være æstetiske at se på, så barnet har lyst til at spise. Samtidig skal madkassen helst tømmes, idet tømning er et udtryk for forældrenes evne til at ramme barnets smag. Hvis madpakken ikke tømmes, pakkes madderne måske ind og bringes med hjem. Både som en indikation på hvad barnet ikke har spist, noget som forældrene på denne måde reelt ved, og dermed til en debat om den næste madpakke. Madkassen er fyldt med familien - dels i det arbejde, der er gået i at smøre madpakken, dels i de præferencer, som indholdet udtrykker. Præferencer, som er individuelle men indenfor familiens felt.

\section{Madpakken som format}

Ud fra interviewene med de "sunde" familier, hvori deltog både børn og voksne, blev det tydeligt at der i relation til frokosten (indtaget væk fra hjemmet) og barnet er distinkte perioder barndommen igennem. I vuggestuen eller dagplejen kan det være institutionen der sørger for maden, i børnehaven har det frem til lovvedtagelsen om mad i daginstitutioner været mest almindeligt, at børnene havde mad med hjemmefra, typisk i form af en madpakke. Også i skoletiden er det mest almindeligt, at børnene har en madpakke med hjemmefra, i hvert fald til de når en vis alder. Forholdene varierer lidt, for på nogle skoler har man frokost og frugtboder hvor børnene kan købe frokost. Eventuelt er boden del af et andet projekt, f.eks. er det nogle steder de ældre klasser, som kører dem (laver maden), med henblik på at tjene penge til klassetiltag.

Måltidet som format betyder at der er spilleregler for, hvad man kan og ikke kan i relation til det enkelte måltid. Disse spilleregler er kulturelle, al den stund at måltidsformaterne er forskellige mellem forskellige kulturer, samtidig med at de indenfor den enkelte kultur ligger forholdsvist fast. Hvis vi tænker på de danske måltidsformater, er det klart, at vi uden problemer kan udskille 3 hovedmåltider: morgenmad, frokost og aftensmad. At de har specifikke navne, er med til at understrege denne klassifikation. Men vi kan foretage andre opdelinger. F.eks. er det forskelligt, hvad man spiser til de tre måltider, hvoraf nogle fødevarer ikke kan flyttes fra det ene mål- 
tid til det andet mens andre hører hjemme ved flere måltider. Et eksempel på det ikke flytbare er den varme mad med f.eks. sovs, som spises om aftenen, som ikke problemløst kan flyttes til om morgenen, men måske til frokosten, klassificeret som f.eks. en lille varm ret eller rester. Andet, så som mælk, kan indpasses i forskellige måltidsformater. Madpakken er i høj grad et måltidsformat, et format som har den store fordel:

"At den består af så få, velkendte og overskuelige ingredienser, som man hurtigt kan danne sig et overblik over. Man - familien - kan sammensætte sin frokost, så den passer til dens opfattelse af, hvad der smager godt og er sundt. Brød med pålæg er nok den form for mad, der hurtigst, lettest og billigst lader sig fremstille og variere på en sund måde"(Büchmann 1992) 56).

Madpakken er et format som man ikke sådan kan ændre fra den ene dag til den anden. Det skal ikke forstås som at den ikke kan ændres - al kultur er løbende under forandring - men forandring kan kun ske, når man har det ene ben i den hverdagsbaserede trygge selvfølgelighed og det andet i forandringen.

Tager man udgangspunkt i den sociale situation hvor maden spises, er der også store forskelle. I vuggestuen og dagplejen er det personalet, der bestemmer over spisesituationen. I børnehaven er det også personalet, der at sætte regler op for spisesituationen, herunder om der må tales, om alle skal starte med at spise madpakken samtidig, og om madpakkens indhold skal spises i en bestemt rækkefølge mm (se også Smith, 2003). Forældrene i de "sunde" familier giver udtryk for, at de finder, at det er i orden. Men når personalet begynder at sætte regler op for hvad der må puttes i madkassen, så "går de til kamp", som de udtrykker det. Stridsspørgsmålet er den kærlighedshilsen, som forældrene lægger i madkassen. En tradition som pædagogerne gerne ville have udryddet, men hvor forældrene fortalte at det var en kamp de tog, for de ville ikke opgive deres rettighed.

Også i de små klasser i skolen overvåger lærerne spisningen af madpakkerne. Når børnene imidlertid bliver så gamle at de spiser uden overvågning, er det de andre børn, der er med til at bestemme indholdet i madpakken. Det gælder især æg og ost, som børnene siger, "lugter". Pålæg som de gerne spiser, når de er hjemme, men som de ikke vil have med i madpakken.

\section{Madpakkens budskaber, madpakkens symbolik}

I relation til tiden, arbejde og familien er hverdagene, som familien oplever, koncentreret om arbejde og institution. Fem dage om ugen arbejdes der, og 2 dage 
holder man fri fra arbejde. Når madpakken er så vigtig for forældrene og for familiens funktion, hænger det selvfølgelig sammen med at:

"Madpakken er et af de få direkte bidrag, som forældrene giver til børnenes liv $\mathrm{i}$ institutionen. Madpakken har stor betydning for børn. Ikke kun som mad men også følelsesmæssigt. Madpakken er et lille stykke "mor" og "far" - en forbindelse til hjemmet, som knyttes hver gang, der spises frokost. Det er let at forvisse sig om, at det forholder sig sådan, når man ser børn åbne for deres madpakker. Det kan resultere i mange reaktioner og udtryk: fra glæde og forundring til vrede og tavshed. Men de reagerer altid" (Smith, 2003:230).

Skriver Smith med udgangspunkt i etnografiske observationer i børnehaver.

Madpakken er med til at indprente barnet hjemmets madkultur, som bliver noget taget for givet. Men samtidig er spisesituationen også et bindeled i familierne, maden hjemmefra er bindeleddet mellem forældre og børn. At dele mad (også via en madpakke) er en del af det antropologen Mauss (1954: 12) kalder "the gift relationship", en form for symbolsk udveksling, hvorigennem sociale bånd etableres og forstærkes. Gavegivning er nemlig en cyklus af sociale situationer: gavegivning, gavemodtagelse og endelig en ny gavegivning fra den, der før modtog. For barnet er gaven maden i madkassen, gavemodtagelsen er at spise maden.

For barnet er indholdet genkendeligt og velkendt. Madkassen kan pakkes så den er let at pakke ud, og en vedlagt serviet signalerer andet, der hører måltidet til. At der ikke spildes, at mad om munden tørres af med serviet etc. Madkassen er således ikke bare god ernæring, men også i høj grad med til at socialisere barnet omkring måltidet. En socialisering, som vel at mærke er iscenesat af forældrene. For børnene er madkassen med til at signalere at en madkassedag er en hverdag, $\mathrm{i}$ modsætning til ikke-hverdage, hvor der ikke spises mad fra madkasser.

Men madpakken har også fordele for daginstitutionens personale, da indholdet er tilpasset børnenes smag betyder det, at der bliver færre problemer i spisesituationen.Madpakken henleder opmærksomheden på en anden vigtig distinktion $\mathrm{i}$ hverdagslivet, nemlig modsætningen mellem hjemme og ude. Hjemmet som samlingssted for familien og det, der er udenfor som det modsatte og fremmede. Daginstitutionen eller skolen kan aldrig sammenlignes med hjemmet, uanset hvor hyggeligt der er. I relation til denne modsætning er madpakken budbringeren, der følger barnet på tværs af grænsen. Den indeholder familie, selvom familien ikke er der. Den udtrykker forbundethed. Et citat fra et interview udtrykker madpakkens kompleksitet og symbolik: "Jeg har det sådan, at når de åbner madpakken, så skal 
den være meget hjemmefra, og så meget $i$ den, som jeg ved at de kan lide. Så er det ikke længere en madpakke i gængs forstand, fordi så er det ikke fire flade, det er noget hjemmefra. Og så siger de "nej, hvor skønt, det har min mor lavet til mig, eller min far". De spiser den jo selvfølgelig ikke med mig, men de har mig med i madpakken, det synes jeg er vigtigt" (interview. fam. B).

Haastrup betegner skolemaden "min mors egen madpakke" som en navlestreng til alt det derhjemme, mest på godt, men af og til på ondt. Madpakken repræsenterer barnets hjem i skolen overfor de andre elever og overfor læreren" (Haastrup, 2003: 250).

I relation til madpakker og forbundethed er det tydeligt at der sker en ændring i relation til børnenes alder. Forbundetheden og familien er stærkest i relation til børnehavebørn og de yngre skolebørn, hvor maden både har en lille hilsen hjemmefra og ikke spist mad bliver taget med hjem.

Når børnene bliver ældre bliver maden stadig smurt hjemme, men den bliver ikke nødvendigvis bragt med hjem og når børnene når de ældste klasser forsvinder madpakken, og erstattes af deres egne bestemmelse af hvad og hvornår de vil spise. Reelt følger madpakken således en samfundsideologi om at de unge skal frisættes og bære ansvaret for sit eget liv (se også Nielsen 2003).

\section{Den lille hilsen hjemmefra}

Den lille hilsen hjemmefra er oftest, men behøver ikke at være det, noget sødt. Således får 3-årige Paprika en ostehaps med i madkassen. At ostehapsen alene hører madkassen til, ses af at hun ikke spiser ostehaps i weekenden. Ostehapsen understreger at det ikke er indholdet, men den klassificering og dermed betydning, som fødevaren har, der har betydning. Ostehapsens betydning er madkasse, og dermed hverdag, og forbundethed, ikke samvær i relation til spisningen. Et andet barn, hvor maden følger et lignende mønster, er Ritt, børnehavebarn på 5, som får pålægschokolade med i børnehaven, men ikke spiser det i andre sammenhænge. Det samme forhold finder vi hos hendes storesøster Rebecca på 6, som spiser pålægschokolade om hverdagen men ikke i weekenden.

James (1990) har et bud på slikkets problematiske status. Ifølge hende er årsagen, at slik ${ }^{4}$ er vanskeligt at klassificere og derfor falder udenfor den almindelige klassifikation. Slik er spiseligt, men det er ikke mad, fordi det ikke spises til måltiderne. Det falder således mellem kategorierne mad og ikke-mad. James skriver: 
"The cultural role allotted to confectionary is that of evil sprite, tempting and destructive. Because of its high sugar and fat content confectionary receives little acclaim and much condemnation from the health professionals" (James 1990: 669).

Samtidig har slik, f.eks. chokolade, en symbolsk rolle i forhold til sociale relationer, som udveksling af søde sager - tænk på chokoladeæsken til værtsparret ved en fest - er med til at etablere og opretholde.

\section{Kampen om madpakken}

Madpakken befinder sig i dag i skæringspunktet mellem hjem (familie) og stat. Familien og madpakken er, som det også understreges i denne artikel, del af en større historisk proces, og familien (og madpakken) er forbundet med politiske og økonomiske strukturer.

Dette forhold illustreredes, da folketinget i 2008 besluttede at der skulle indføres en ny madordning i daginstitutionerne, så forældrene undgik at smøre madpakker. Ordningen skulle være forældrebetalt, men mange forældre ville ikke have ordningen. De argumenter forældrene brugte ${ }^{5}$, var mange af de samme temaer, som er gået igen i denne artikel, nemlig:

- At de bedst vidste, hoad deres børn ville spise - og at børn skal spise det de kan lide

- At de ønsker at præge deres barns mad-og spisevaner

- At det er et forældreansvar at smøre sit barns madpakke, som de gerne påtager sig.

- At de ville miste den viden, de fär via den hjembragte mad.

- At familier, der havde problemer med at give deres børn sund mad, selvfølgelig skulle hjælpes.

Når forældrene reagerer så stærkt på politikernes bestemmelse omkring mad i børneinstitutioner er det fordi dét, politikerne giver udtryk for, er at det alene er et spørgsmål om kost, det vil sige at børnene får den rigtige, ernæringskorrekte mad i det daglige. De udtrykker ikke nogen forståelse for de andre funktioner, som maden også har, og som er beskrevet i denne artikel.

Madpakken er ikke noget, som man bare politisk kan bestemme skal afskaffes, ikke engang i sundhedens navn.

Politikerne overser også den betydning der ligger i, at man i nogle familier inddrager børnene i madlavningen, det vil sige et socialiserende aspekt, en proces hvor barnet indføres i familiens spisevaner og begrundelser for disse. For børnene skal 
ikke deltage i madlavningen i børneinstitutionerne med den nye ordning, og det betyder, at den sundhedseffekt, som der er i at opdrage børn til at lave mad mistes.

\section{Konklusion}

I samfund, hvor der ikke er adskillelse mellem arbejde og hjem, skal børn kun forholde sig til en arena, hvor hverdagslivet udspilles og opdragelse finder sted, I samfund, hvor arbejde og hjem er adskilt, og hvor begge parter arbejder væk fra hjemmet, skal barnet passes af andre. I det danske samfund betyder det at børn tilbringer adskillige timer i institution. Det betyder at barnet skal bevæge sit hverdagsliv mellem to kulturer: hjemmets og institutionens, og her spiller madpakken en væsentlig rolle. For den enkelte familie har madpakken betydning når den smøres, for her tilpasses og defineres familiens smag. Men madpakken har også betydning når den spises af familiens børn i daginstitutionen/skolen, i en situation hvor familien ikke er til stede, og som den ikke har kontrol over. Madpakken bliver bindeleddet - den skaber forbundethed i den ikke-samlede familie. Madpakkens store fordel er, skriver Büchmann (1992: 56):

"At den består af få, velkendte og overskuelige ingredienser, som man hurtigt kan danne sig et overblik over. Brød med pålæg er nok den form for mad, der hurtigst, lettest og billigst lader sig fremstille.."

Madpakken har gennem historien vist sig at være et særdeles funktionelt og levedygtigt koncept.

\section{Noter}

1. Velbekomme er det ord, der er skrevet på en meget brugt røde blikmadkasse. Det møder spiseren inden madkassen åbnes og det møder igen, når madkassen efter spisningen lukkes. Nielsen (1991:490). Velbekomme betyder således "må det bekomme dig vel". Velbekomme er dels en hilsen hjemmefra, en forbundethed indenfor familien. Men samtidig ligger der et socialiserende/ opdragende element, sendt fra familien til et af dens medlemmer. Den betydning der udtrykkes er familien overfor "andre" i antropologisk forstand. Samtidig er velbekomme også noget, man traditionelt ønskede andre, når man f.eks. kom ind i et lokale hvor mennesker spiste, ville man ønske dem velbekomme.

2. Anførselstegnet omkring "sund" hentyder til at det som udgangspunkt var et tomt begreb, som familierne skulle udfylde via fortællingen om deres praksis. 
3. Den "sunde" familie - den "sunde" krop, som var et tværvidenskabeligt forskningsprojekt blev gennemført på Odense Universitet i perioden 1996-2003.

4. Artiklen beskæftiger sig med det, der på engelsk hedder confectionary, og som indeholder slik, marmelade, frugt på dåse, kager, småkager, mm. Confectionary er en klassifikation, som ikke som sådan lader sig oversætte til dansk. Jeg har valgt at fokusere på det James skriver om slik og sødhed.

5. Alle aviser jeg har brugt, er morgenblade. Jeg har ikke i gennemgangen fokuseret på, hvordan de enkelte aviser italesætter det politiske budskab om den politisk vedtagne landsdækkende madordning. Der er politiske forskelle, men de er ikke i fokus her. Alle kan følge debatten via avisernes hjemmesider. Jeg citerer fra flere artikler i henholdsvis Jyllandsposten og Politiken i perioden 6. november 2009 - 21. Januar 2010. Jeg har også gennemset hjemmesider. I relation til debatten omkring tvungen madordning er det interessant at sammenligne det, der fokuseres på i henholdsvis avisartikler, læserbreve og interviews i radio og fjernsyn. Avisartikler bygger ofte på enqueter for at skabe en generel belysning af en problemstilling. En enquete er typisk, at man kontakter ca. 1500 repræsentativt udvalgte borgere og stiller dem nogle spørgsmål. Spørgsmål, som har faste svarmuligheder. Det man får og kan præsentere i avisen er derfor svar på de spørgsmål man selv har sat op. Hvis man derimod interviewer mennesker via eksplorerende interviews, eller observerer deres daglige handlen, får man indsigt i variationen, og i multiple og forskellige forklaringer og holdninger. Det samme sker, når mennesker skriver læserbreve eller andre selvformulerede indlæg. Her tages også udgangspunkt i deres konkrete levede liv og i de perspektiver, de finder det relevant at tage frem. De forskellige måder at gribe en problemstilling an på vil således præsentere forskellige aspekter af den samme problemstilling. Aspekter som kan virke som om de er modsætninger, men som reelt er udtryk for forskellige måder at indsamle empirisk materiale.

\section{Litteratur}

Allison, A. (1997). Japanese Mothers and Obentos - The Lunch-Box as Ideological State Apparatus. In C. Counihan \& P. van Esterik (red.): Food and Culture, New York and London: Routledge.

Bühlmann, R. \& Püschl, S. (1992). Madpakken - træk af spisevanernes historie. København: Forlaget Fremad.

Carsten, J. (2004). After Kinship. Cambridge: Cambridge University Press

Delaney C. (2004). Investigating Culture - An Experimental Introduction to anthropology. Oxford: Blackwell Publishing

Douglas, M. \& Nicod, M. (1974). Talking the biscuit: the structure of the British Meal. New Society 30: 744-747

Douglas, M. (2003). Standard Social Uses of Food. In M. Douglas (red.): Food in the Social Order. Studies of Food and Festivities in Three American Communities. London and New York: Routledge.

Elverdam, B. \& Scott-Sørensen, A. (red.) (2003). Den sunde familie - den sunde krop. København: Munksgaard Danmark. 
Martin, F. (2003). Interpreting Everyday Culture. London: Arnold

Haastrup, L. (2003). Mad og måltider i skolen. In L. Holm (red). Mad, mennesker og måltider - samfundsvidenskabelige perspektiver, København, Munksgaard Danmark

Jakobsen, G.S. \& Jensen, A.M.B. (2007). Fuld af korn - en antropologisk undersøgelse af faglærte og ufaglærte danskeres hverdagserfaringer med brød og fuldkorn. Kræftens Bekæmpelse.

James A. (1990). The good, the bad and the delicious: the role of confectionary in British society. The Sociological Review 38 (4): 666-688.

Lévi-Strauss, C. (1997). The Culinary Triangle. In C. Counihan \& P. van Esterik (red.): Food and Culture, New York and London: Routledge.

Mauss, M. (1970). The Gift. Forms and Functions of Exchange in Archaic Societies. London: Routledge \& Kegan Paul.

Mintz, S.M. (1997). Time, Sugar, and Sweetness. In C. Counihan \& P. van Esterik (red). Food and Culture. New York and London: Routledge

Møhl, P. (2003). Synliggørelsen - med kameraet i felten [Making visible - with the camera in the field]. In K. Hastrup (red) Ind i verden - en grundbog $i$ antropologisk metode. København: Hans Reizels Forlag

Nielsen, M.K. (2003). Frigørelse, frisættelse og risiko i de unges forhold til mad og sundhed. In B. Elverdam \& Sørensen (red) (2003)

Nielsen, N.K. (2003). Madkultur - opbrud og tradition. Århus: Klim.

Nielsen, N.Å. (1991). Ordenes historie. Dansk Etymologisk Ordbog, København: Danmarks Nationalleksikon.

Olsen, N.V. (2003). Måltider og sundhed i danske børnefamilier. In B. Elverdam \& Sørensen (red) (2003)

Smidt, S. (2003). Måltider i daginstitutioner for børn. In L. Holm (red). Mad, mennesker og måltider - samfundsvidenskabelige perspektiver. København: Munksgaard Danmark

Tjørnhøj-Thomsen, T. (1998). Tilblivelseshistorier. Barnløshed, slægtsskab og forplantningsteknologi i Danmark. Københavns Universitet: Ph.d.-afhandling.

Watson, J.L. \& Caldwell, M.L. (red) (2005). The Cultural Politics of Food and Eating: A Reader. Blackwell Publishing: Oxford 